Sharif University of Technology
Scientia Iranica
SCIENTIA
IRAN ICA
http://scientiairanica.sharif.edu

\title{
Experimental and numerical study of a proposed moment-resisting connection for precast concrete frames
}

\author{
M. Fathi*, M. Parvizi, J. Karimi, and M.H. Afreidoun \\ Department of Civil Engineering, Razi University, Kermanshah, Iran. \\ Received 4 July 2016; received in revised form 6 December 2016; accepted 13 March 2017
}

\author{
KEYWORDS \\ Experimental study; \\ Precast concrete \\ frame; \\ Moment-resisting \\ connection; \\ Cyclic loading; \\ Finite-element \\ analysis.
}

\begin{abstract}
This paper presents the test results of a proposed ductile moment-resisting beam-column connection for precast concrete frames and a developed 3D nonlinear finiteelement model of this connection featuring several different details to predict its behavior under cyclic loading based on the loading of ACI T1.1-01. In this connection, precast concrete beam and column are connected to each other by steel linkage element. This method is able to create concrete structures of higher quality by minimizing in-situ concreting, maximizing the speed of construction, and using ductile and exchangeable elements in sensible locations of the connection. Two types of bolted and welded connections were compared with the monolithic connection in terms of stiffness, strength, energy dissipation capacity, and ductility factor. All specimens satisfied all criteria of ACI T1.1-01. To investigate the behavior of these connections, a 3D nonlinear finite-element model was simulated. Numerical results showed good agreement with experimental results. The initial stiffness of monolithic connection specimen was greater than that of bolted connection and welded connection specimens. Even though the beam's moment capacity of the two welded and bolted samples was slightly more than that of monolithic sample, the ductility factors in these samples were slightly less than those in monolithic sample.

(C) 2018 Sharif University of Technology. All rights reserved.
\end{abstract}

\section{Introduction}

Precast technology is one way to construct reinforced concrete structures. Precast structures have different advantages such as high quality control, economical cost, and speed on erection. The quality of connection of precast elements to each other is one of the most important parameters for seismic behavior of precast structures. Precast concrete structures are mainly used

*. Corresponding author. Tel.: 988334274530

E-mail addresses: fathim@razi.ac.ir (M. Fathi);

parvizi.mahdi@razi.ac.ir (M. Parvizi); j.karimi@razi.ac.ir

(J. Karimi); afreidoun.mohammadhoseein@razi.ac.ir (M.H. Afreidoun).

doi: $10.24200 /$ sci. 2017.4200 as a simple frame with a simple connection of beam to column and cast-in-place shear wall. During the last decades, a high number of researches have been done on the connections in precast structures. Kataoka et al. [1] conducted a numerical and experimental study to investigate the behavior of a specific type of beamcolumn connection. This type of connection was created by concrete corbels, dowels, and continuity bars, passing through the column. Guan et al. [2] conducted an experimental study to develop a new beam-tocolumn connection for precast concrete frames. The proposed connection showed good seismic resistance, hysteretic behavior, strength, deformability, stiffness, and energy dissipation. Choi et al. [3] proposed a precast concrete beam-to-column connection using embedded steel end plates in beam and column. The 
joint performance was evaluated based on connection strength, stiffness, energy dissipation, and drift capacity. Shariatmadar and Zamani Beydokhti [4] presented three types of precast concrete connection with different details, namely straight spliced, U-shaped, and U-shaped with steel plate. The first one has similar behavior to monolithic connection. Zoubek et al. [5] developed a nonlinear finite-element model of centric dowel connections in precast buildings. Several material and interaction parameters were included and their effects were investigated. Negro et al. [6] and Bournas et al. [7] conducted pseudo-dynamic tests on a fullscale 3-storey precast concrete building. Their study showed good behavior of a precast concrete system. Vidjeapriya et al. [8] used a precast concrete connection in which beam is connected to column with corbel using (i) dowel bar and (ii) dowel bar with cleat angle. In terms of ductility, the precast specimen, using dowel bar and cleat angle, showed better behavior than the monolithic specimen did. However, in terms of strength and energy dissipation, the monolithic specimen had better behavior. Smith et al. [9] used a spring element to simulate welded steel connector assemblies between adjacent girders in decked precast pre-stressed concrete girder bridges. Senel and Kayhan [10] conducted a case study to explore precast building fragility based on damage assessment using non-linear time history analysis. Ertas et al. [11] carried out a series of tests. In these tests, many models were developed and investigated using cast-in-place concrete in the beamcolumn connection.
However, the main body of the research activities in precast technology was conducted by NIST (National Institute of Standards and Technology) [12] in the US. The main idea of their proposed connections was to implement post-tension cables with mild steel or hybrid connection. The actions of the committee were divided into four phases. In each phase, the tests were planned and administered considering the deficiencies in the prior phase to improve the connection behavior. The main variables in these experiments were the amount of mild steel, location of post-tensioned cables, and the post-tensioning force.

In the present study, a type of connection system for moment-resistant precast concrete frames is proposed. This connection system consists of steel linkage element connected to the column by bolts and to the beam by bolts or welding. This method is able to create concrete structures of higher quality, rather than cast-in-place structures, by minimizing insitu concreting, maximizing the speed of construction, and using ductile and exchangeable elements in sensible locations of the connection. In addition, the 3D finiteelement models of these connections are developed using ABAQUS software to predict the behavior of this type of connection. Then, the results of numerical study are compared to those of experimental study.

\section{Test procedure}

The cross-sections of beam and column are shown in Figure 1. The mechanical properties of the material

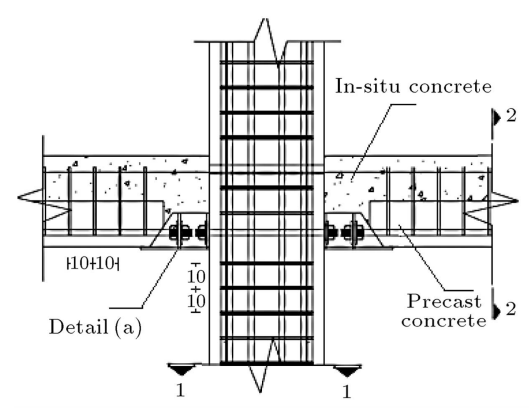

(a) BC specimen
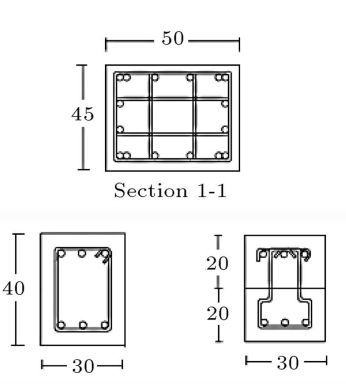

Section 3-3 Section $2-2$

(d) Beam and column sections

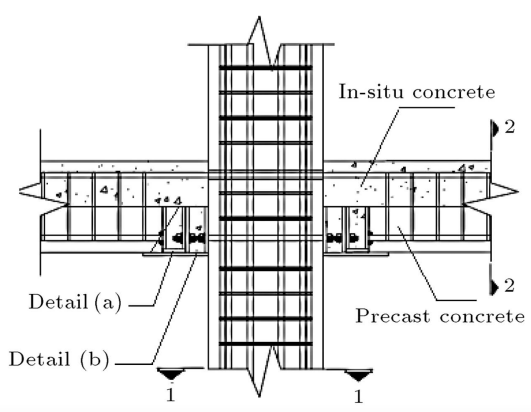

(b) WC specimen

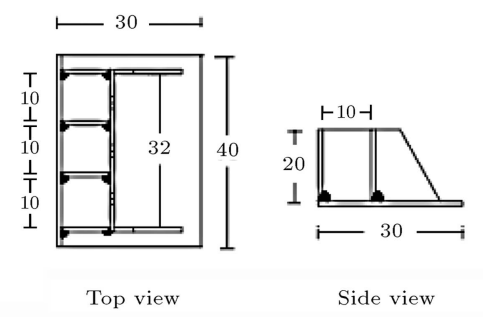

(e) Detail (a)

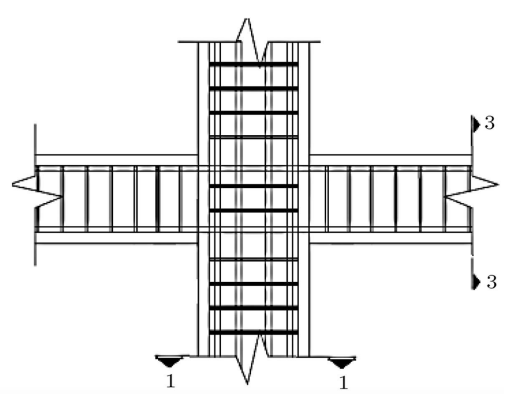

(c) MC specimen

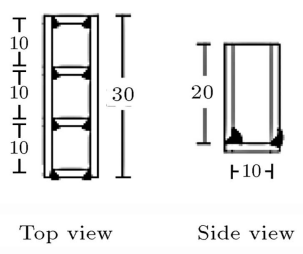

(f) Detail (b)

Figure 1. Details of specimens and steel linkages; all dimensions are in cm. 
Table 1. Mechanical property of materials.

\begin{tabular}{lccc}
\hline Material & $\begin{array}{c}\boldsymbol{f}_{\boldsymbol{c}}^{\prime} \\
(\mathbf{M P a})\end{array}$ & $\begin{array}{c}\boldsymbol{f}_{\boldsymbol{y}} \\
(\mathbf{M P a})\end{array}$ & $\begin{array}{c}\boldsymbol{f}_{\boldsymbol{u}} \\
(\mathbf{M P a})\end{array}$ \\
\hline Concrete & 35 & - & - \\
Steel & - & 240 & 370 \\
Reinforcement & & 400 & 600 \\
\hline
\end{tabular}

are presented in Table 1 . All specimens were designed according to ACI 318-05 code provisions. For all specimens, the column's longitudinal reinforcement ratio was $2 \%$, and spacing of the closed stirrups was approximately $10 \mathrm{~cm}$.

The specimens were identified to be $\mathrm{BC}$ (Bolted Connection), WC (Welded Connection), and $\mathrm{MC}$ (Monolithic Connection). The main idea for construction of $\mathrm{BC}$ and $\mathrm{WC}$ specimens was to connect the beam to the precast column using a steel linkage element. Therefore, first, the steel linkage was made using the welding technique, and all welds were tested with Ultrasonic Test (UT) to assure the quality of welding. The details of this steel linkage are demonstrated in Figure 1. The steel linkage was connected to precast column by embedded threaded bolts. The bolts were made of A325 steel with the strength of $F u=800 \mathrm{MPa}$.

The construction of beams was performed in two steps. First, the lower half of the beam was made in the factory in the precast form. Then, the half-beam was connected to the steel linkage with nuts and washers for the BC sample (Figure 1(e)). It was also connected to bars welded to the end of the beam and aiding steel element to the steel linkage element in the WC sample (Figure 1(f)). In the second step, the upper half beam was constructed in-situ; after fastening the stirrups to the reinforcements (Figure $1(\mathrm{~d})$ ), the upper half beam was concreted along with the slab, and the concrete frame was completed. The details of the three samples are represented in Figure 1.

The test setup was designed to apply the procedure and scheme specified in ACI T1.1-01. Acceptance criteria for moment-resisting frames are based on structural testing (Figure 2). The precast concrete column was supported on a pinned support at base, a roller-supported "hinge end" was designed for the beam, and the top of the column was free to move and rotate. No axial load was applied to the column. On the top of the column, two hydraulic actuators were used, one of which imposed some load, while the other was away from the column. After imposing a proper level of load, the hydraulic pressure of the first actuators was discharged, and the second actuator imposed the load on the top of the column in an opposite direction. The lateral load increased gradually to achieve the pre-determined story drift. To prevent the beam and column out of the frame movement, some lateral bracings were installed. Top displacement of
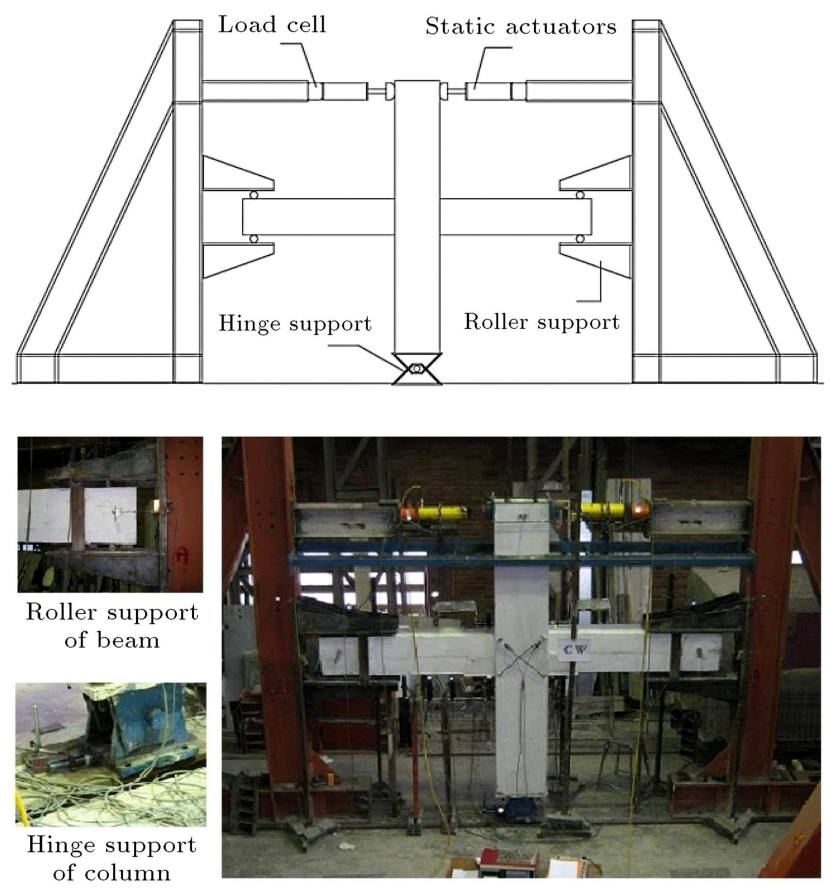

Figure 2. Test setup of specimens.

the column was measured using a linear potentiometer mounted at the level of the hydraulic actuators.

The imposed loading on the samples was performed according to the ACI T1.1-01. This code uses a displacement control method for loading specimen and considers specific criteria for displacement pattern including:

- Three full cycles should be applied at each drift ratio;

- The initial drift ratio should be within the essentially linear elastic response range for the module. Subsequent drift ratios should be the values which are not less than one and one-quarter times and not more than one and one-half times the previous drift ratio;

- Loading should gradually continue with increasing drift ratios until the drift ratio equals or exceeds $3.5 \%$ (ACI T1.1-01).

Considering the above criteria, the following loading pattern (displacement) was chosen to be applied to the specimens (Figure 3 ).

\section{Finite-element modeling and analysis}

The finite-element software ABAQUS 6.9 was used to model and analyze the samples mentioned above. The effects of nonlinearity of material, geometry and contact between different parts of the model as well as bond-slip effect of reinforcement bars were taken into account. Figure 4 shows a view of the FE model. 


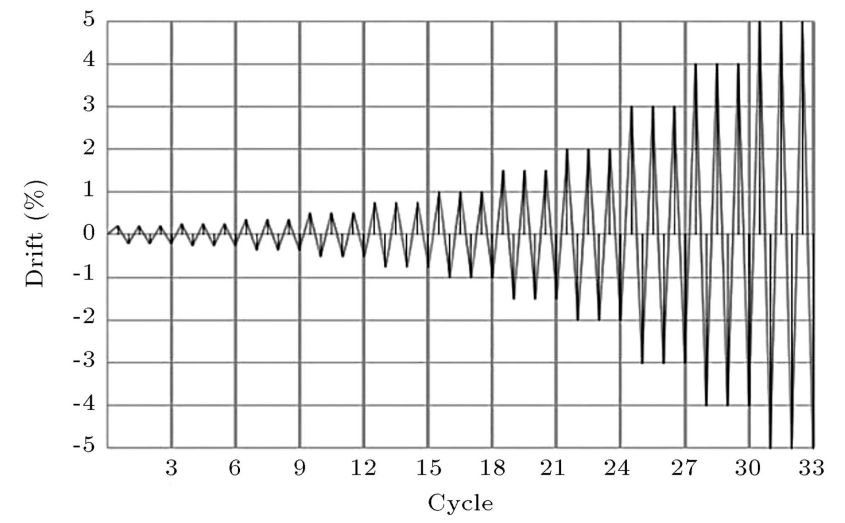

Figure 3. Loading pattern imposed to specimens.

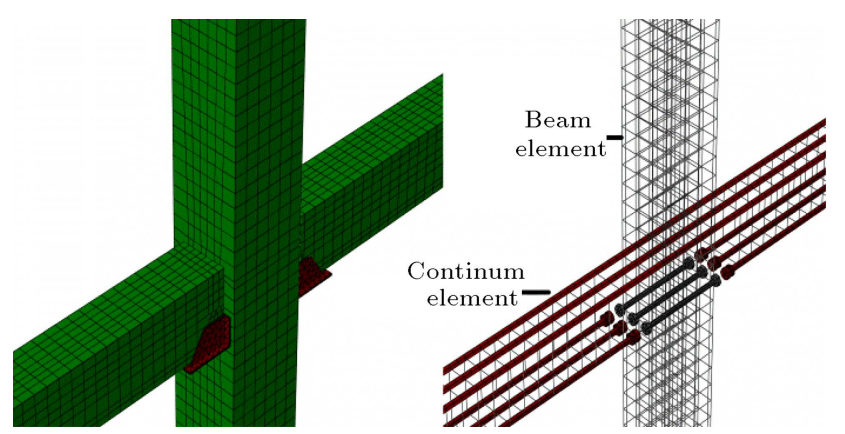

Figure 4. Finite-element modeling.

To model the concrete, an eight-node 3D solid element with reduced integration (C3D8R) and fournode tetrahedral 3D solid elements for steel linkage were considered. Two types of element were used for reinforcing bars. To define the interaction between the end of rebars and welds or bolts of steel linkage and also to consider the bond slippage of upper rebars of beam in the column, 3D elements of C3D8R should be used. For other cases, 3D two-node elements (B31beam element) were considered. These two types of elements are tagged in Figure 4.

A linear kinematic hardening model was used to simulate the behavior of steel materials as they are subjected to cyclic loading. In this model, a stressstrain curve of steel materials is bilinear, and the slop of the second part is considered as $0.01 E$ [13]. The elastic modulus and Poisson's ratio of steel were defined as $2.1 \times 10^{5} \mathrm{MPa}$ and 0.3 , respectively. Concrete damage plasticity model was used to simulate the concrete behavior under cyclic loading. This model contains both compressive and tensile stress-strain curves and their corresponding damage parameters. This model shows the degradation of both tension and compression stiffness. As shown in Eq. (1), by using the damage parameters, the stress-strain relation will change as follows:

$$
\sigma=(1-d) \cdot E_{0} \cdot\left(\varepsilon-\varepsilon^{p l}\right),
$$

where $E_{0}$ is the initial elastic stiffness of concrete, and $d$

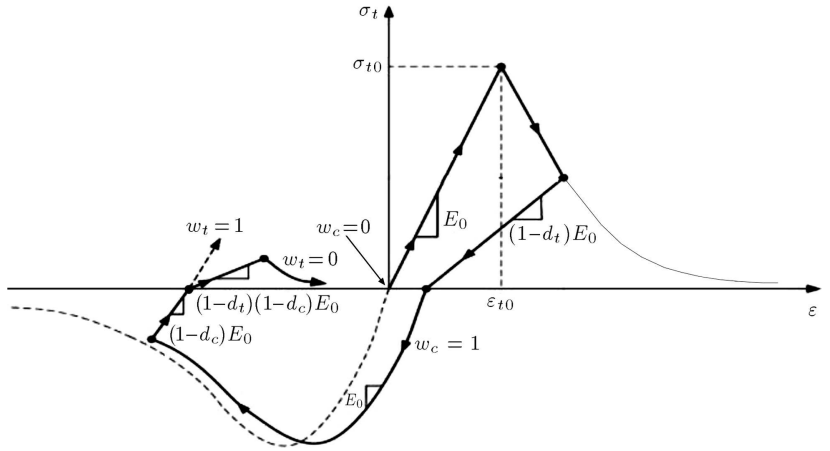

Figure 5. Response of concrete to uniaxial loading in tension and compression [14].

is defined as damage parameter. Figure 5 [14] shows the typical stress-strain curve of concrete for both tension and compression and the effects of damage parameters on the stiffness in recycle loading.

$d\left(d_{t}\right.$ : tensile damage and $d_{c}$ : compressive damage) parameter was computed by the following equation [15]:

$$
\begin{aligned}
& d_{t}=1-\frac{\left(\sigma_{t}+n_{c} \sigma_{t 0}\right)}{E_{c}\left(n_{t} \sigma_{t 0} / E_{c}+\varepsilon_{t}\right)}, \\
& d_{c}=1-\frac{\left(\sigma_{c}+n_{c} \sigma_{c u}\right)}{E_{c}\left(n_{c} \sigma_{c u} / E_{c}+\varepsilon_{c}\right)},
\end{aligned}
$$

where $\sigma_{t}$ is tensile stress, $\sigma_{c}$ is compressive stress, $\sigma_{t 0}$ is tensile strength, $\sigma_{c u}$ is compressive strength, $E_{c}$ is module of elasticity of concrete, $\varepsilon_{t}$ is tensile strain, $\varepsilon_{c}$ is compressive strain, and $n_{t}=1, n_{c}=2$ [15].

To define the interaction between concrete and reinforcement and also bond slippage of bars in a cyclic loading, both normal and tangential behaviors should be considered.

A cohesive model for tangential behavior and a hard contact model for normal behavior were used. For tangential behavior, penalty contact method with friction coefficient of 0.1 was used.

Bond slip was modelled by means of progressive damage concept. Damage is a mechanism that includes two steps in this method: defining damage initiation criterion; introducing a criterion for continuing damage after passing from this initiation point. The cohesive model between reinforcements and concrete was simulated based on the studies done by Murcia-Delso et al. [16]. Progressive damage was simulated according to Figure 6.

Tangential damage is initiated when shear stress reaches $\tau_{\max }=15 \mathrm{MPa}$. The value of $S_{\text {peak }}$ is

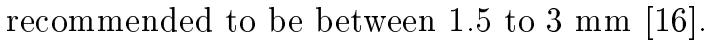

Compressive strength of the concrete was $35 \mathrm{MPa}$ according to the test results of concrete specimens, and the ultimate tension stress of concrete was considered $10 \%$ of the ultimate compressive strength. The detailed 


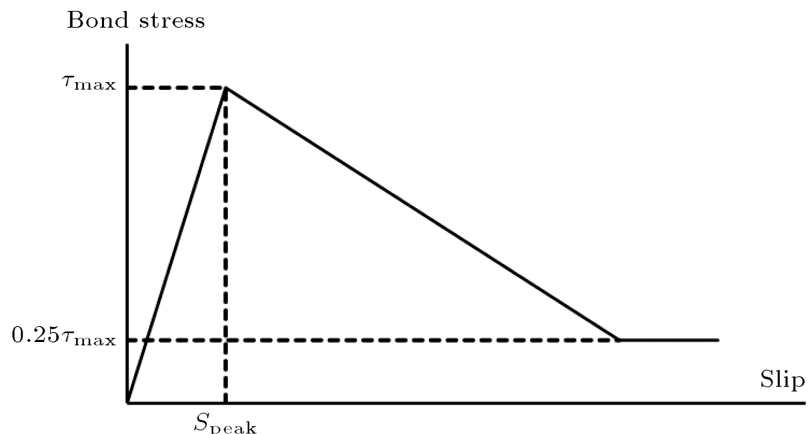

Figure 6. Damage evolution between rebars and concrete.

mechanical properties of materials are presented in Table 1. As shown in Figure 2, the ends of column and beam are defined as hinge and roller, respectively.

\section{Evaluation of test and numerical results}

Figure 7 shows the lateral force versus the story displacement of the specimens for both experimental and numerical results. The behavior of specimens in the initial steps of loading was linear elastic. As the loading proceeds, a crack and, then, more cracks appeared in the specimens; subsequently, the samples passed the ideal level code. Since no loss of strength was observed during these steps, the tests were continued so as to investigate the behavior in further displacements. The $\mathrm{MC}, \mathrm{BC}$, and WC specimens were compared according to their stiffness, strength, and energy dissipation properties. All specimens satisfied all code criteria.

It should be mentioned that the hysteresis curves of samples, especially BC and WC samples, are such that the curves possess a pinching and residual displacement due to:

1. Crack opening and closing during the loading reversals;

2. The interactions among the axial load, shear forces, and bending moments;

3. Lack of appropriate interaction between the concrete and internal surface of the groove at the upper half of beam.

Therefore, the adopted element model must take into consideration both of the material damage and axialshear-flexural interaction in order to predict the response of columns accurately. To make a better comparison between experimental and numerical results, the force-displacement curves of $1.5 \%, 2 \%, 3 \%, 4 \%$, and $5 \%$ drift were plotted individually, depicting the precision of simulation more accurately.

It was observed that the finite-element method and test results are in good accordance with each other. The maximum error percentage of peak strength is about $9 \%$. The little difference between the FE and experimental results in different stages of loading can be attributed to mesh refinement, idealized boundary conditions in the FE model, material nonlinearity, and particularly the way of defining parameters in contact points.

\subsection{Strength degradation}

To assess the strength of the specimens (bearing lateral load capacity), their envelope curves are shown in Figure 7. The envelope curves were obtained by connecting the maximum points in load-drift ratio diagram. The ACI code as an acceptance criterion determines that the ultimate strength of the specimens not be less than $75 \%$ of the maximum strength. It was observed that the strength of the $\mathrm{BC}$ and $\mathrm{WC}$ specimens is greater than that of the MC sample. The WC specimen has both higher resistance value and higher resistance loss than the other two specimens, indicating that weld connection has high resistance and brittle behavior.

Table 2 provides the ratio of ultimate strength to maximum strength $(\alpha)$ and initial stiffness of each specimen. According to this table, all of the specimens met the code acceptance criteria for the ratio of the ultimate strength to the maximum strength. It is obvious that the initial stiffness of $\mathrm{MC}$ specimen has greater value than others, and $\mathrm{BC}$ specimen is stiffer than WC one.

\subsection{Energy dissipation capacity}

According to ACI T1.1-01, for a given cycle, relative energy dissipation ratio, $\beta$, is the area $\left(A_{h}\right)$ inside the lateral force-drift ratio loop for the module divided by the area of the effective circumscribing parallelograms ABCD and DFGA $\left(A_{2}\right)$. The areas of the parallelograms equal the sum of the absolute values of lateral force strengths, $E_{1}$ and $E_{2}$, at drift ratios, $\theta_{1}$ and $\theta_{2}$, multiplied by the sum of the absolute values for drifts ratios, $\theta_{1}^{\prime}$ and $\theta_{2}^{\prime}$ (Figure 8 ).

The relative energy dissipation ratio concept, as described above, was computed from the last cycle of each successive story's drift ratio.

Table 2. Ratio of maximum strength to ultimate strength of specimens.

\begin{tabular}{llcc}
\hline Specimen & $\begin{array}{c}\text { Strength } \\
\text { ratio } \\
(\boldsymbol{\alpha})\end{array}$ & $\begin{array}{c}\text { Initial } \\
\text { stiffness } \\
(\text { ton } / \mathbf{m})\end{array}$ \\
\hline \multirow{2}{*}{ BC } & Experimental & 0.84 & 270 \\
& Numerical & 0.95 & 252 \\
\multirow{2}{*}{ WC } & Experimental & 0.8 & 213 \\
& Numerical & 0.99 & 222 \\
\multirow{2}{*}{ MC } & Experimental & 0.95 & 317 \\
& Numerical & 0.98 & 318 \\
\hline
\end{tabular}



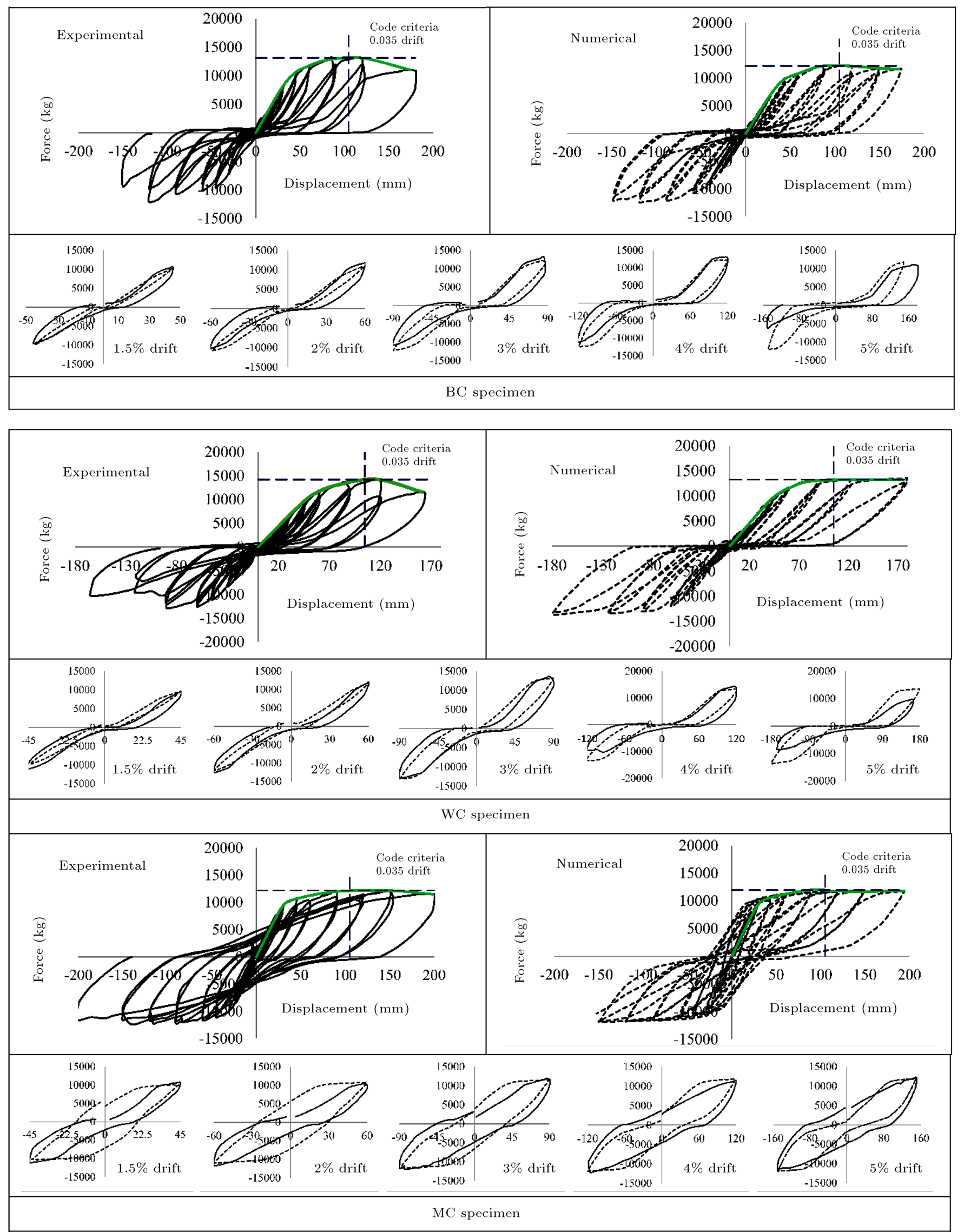

Figure 7. Hysteresis curve of specimens. 


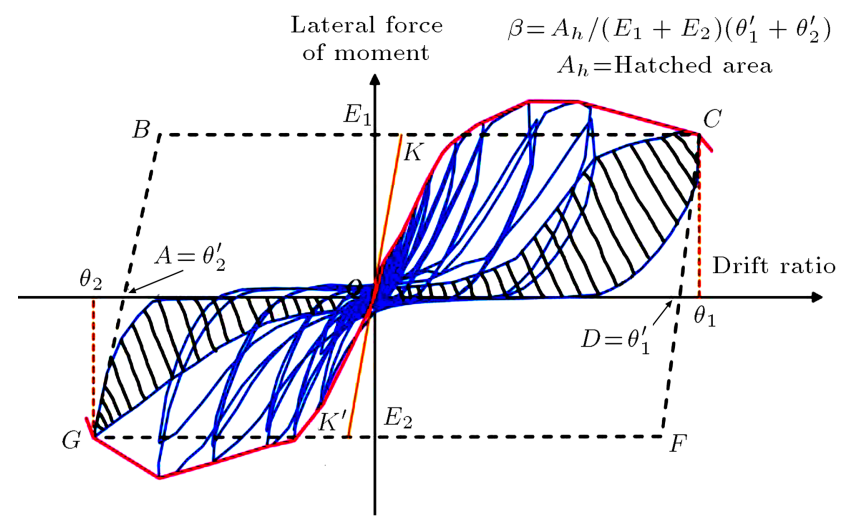

Figure 8. Relative energy dissipation ratio concept.

Figure 9 shows the relative energy dissipation ratio versus the drift ratio for the specimens both experimentally and numerically. The acceptance criterion of ACI T1.1-01 code requires that the relative energy dissipation ratio not be less than 0.125 . This criterion is shown by dashes.

\subsection{Stiffness degradation}

The secant stiffness $\left(K_{\mathrm{sec}}\right)$ calculated at the last cycle of each successive story's drift level was used to compare the stiffness degradations of the specimens. The secant stiffness is defined as the slope of the straight line between the maximum drift levels of that specific load cycle. It is also called "peak-to-peak stiffness". Each secant stiffness value of a specific specimen was normalized $\left(K_{n}\right)$ with respect to the initial secant

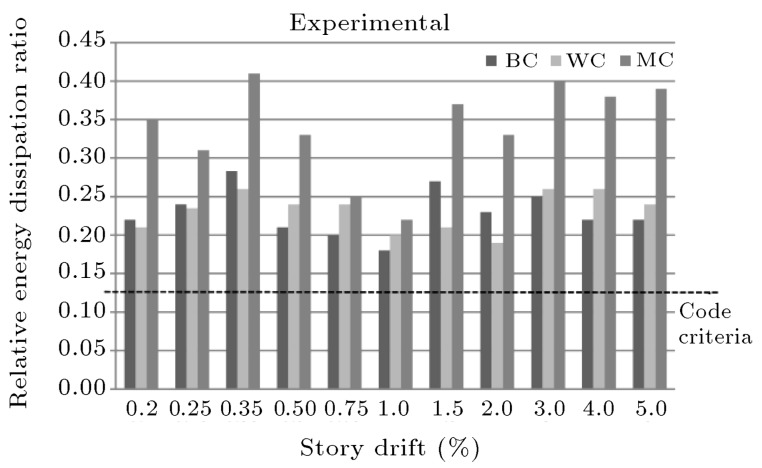

stiffness of the specimen. ACI T1.1-01 code requires that the secant stiffness from a drift ratio of -0.0035 to a drift ratio of +0.0035 not be less than 0.05 times the stiffness for the initial drift ratio. For this purpose, the stiffness degradation of specimens versus story drift for numerical and experimental results is plotted in Figure 10. They are in good agreement with each other. The maximum error percentage of point to point is less than $10 \%$. According to the chart, all specimens are above the acceptance criterion of the code.

\subsection{Behavior of contacts}

To assess the accuracy of numerical simulation in predicting the behavior of connections, some failure modes and deformation shapes predicted by the model were compared with what was observed in experiments. Figure 11 shows deformation of the model in a BC-type connection. In Detail 1, a gap between concrete and

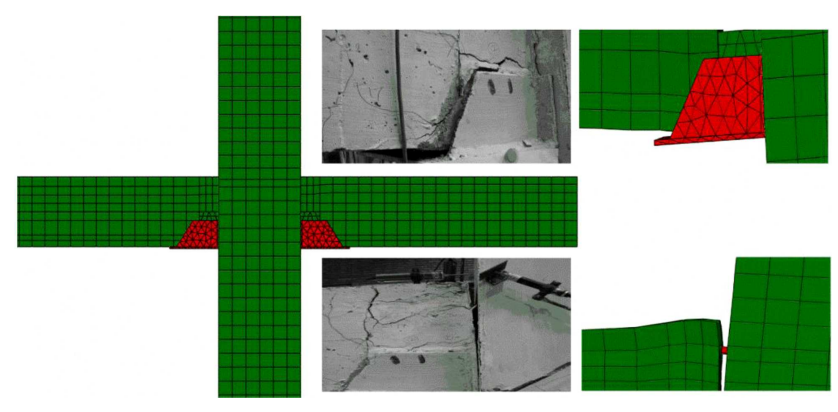

Figure 11. Deformations of contact zone in FEM analysis and test procedure.

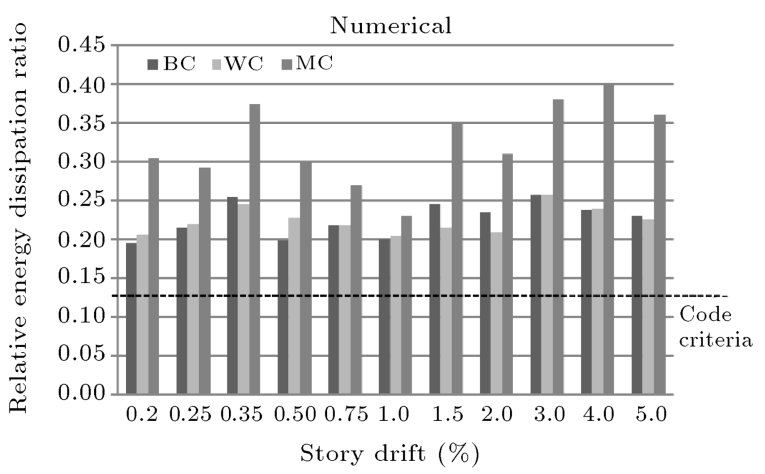

Figure 9. Relative energy dissipation of specimens.
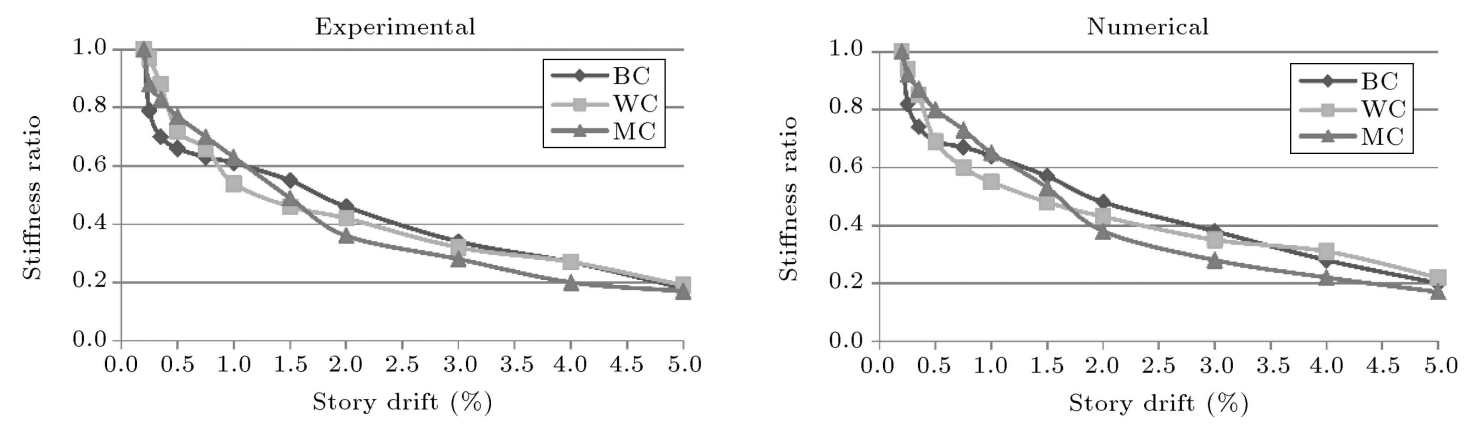

Figure 10. Stiffness degradation of specimens. 
steel linkage was predicted that could be seen in the test, too. In Detail 2, concrete beam was separated from column at contact points. At these points, according to the test observations, contact properties were described well where they act only at compression and allow separation at tension.

\subsection{Ductility factor and flexural capacity of specimens}

Displacement ductility factor, one of the criteria of nonlinear behavior of frame subjected to cyclic loading, is defined as the ratio of displacement at the maximum load to displacement at the yield load, as expressed by Eq. (4):

$$
\mu=\frac{\delta_{\max }}{\delta_{y}} .
$$

The ratio of beam moment capacity $(\Omega)$ is calculated by Eq. (5):

$$
\Omega=\frac{\text { Experimental beam moment capacity }}{\text { Design beam moment capacity }} \text {. }
$$

The values of $\mu$ and $\Omega$ are given in Table 3 . It can be noted that the beam capacity factor $(\Omega)$ for $\mathrm{BC}$ and WC specimens is bigger than that for MC specimen, while this is vice versa in the case of the ductility factor $(\mu)$. This is due to high stiffness of the steel linkage and low ductility of bolted and welded connections in $\mathrm{BC}$ and WC specimens.

\subsection{Pattern of damage}

The crack distribution pattern is one of the best methods to show the real behavior of specimens. In the initial steps of loading, there is no significant difference between the damages in specimens. As the load increases, cracks in monolithic specimen move toward the center of the beam due to an increase in the shear stress at the end of beam. In these tests, no damage occurred in the linkage and all damages occurred in the concrete beams near the steel linkages due to high stiffness and strength of the linkage. Almost in all specimens, the first crack occurred at the end of the beam in cycles 7 and 9 . As the loading proceeds in cycles 14 and 15 , corresponding to $0.35 \%$ drift, the cracks are mainly vertical. Afterwards, the cracks develop to the center of the beam section; ultimately, they find a diagonal form and move toward the panel zone. However, in BC and WC samples, as the load increases, some cracks are created around the steel linkage. In addition, at the top of the beam section, due to slipping of the concrete from the sleeve, the bearing cracks cause the concrete to be crushed. Figure 12

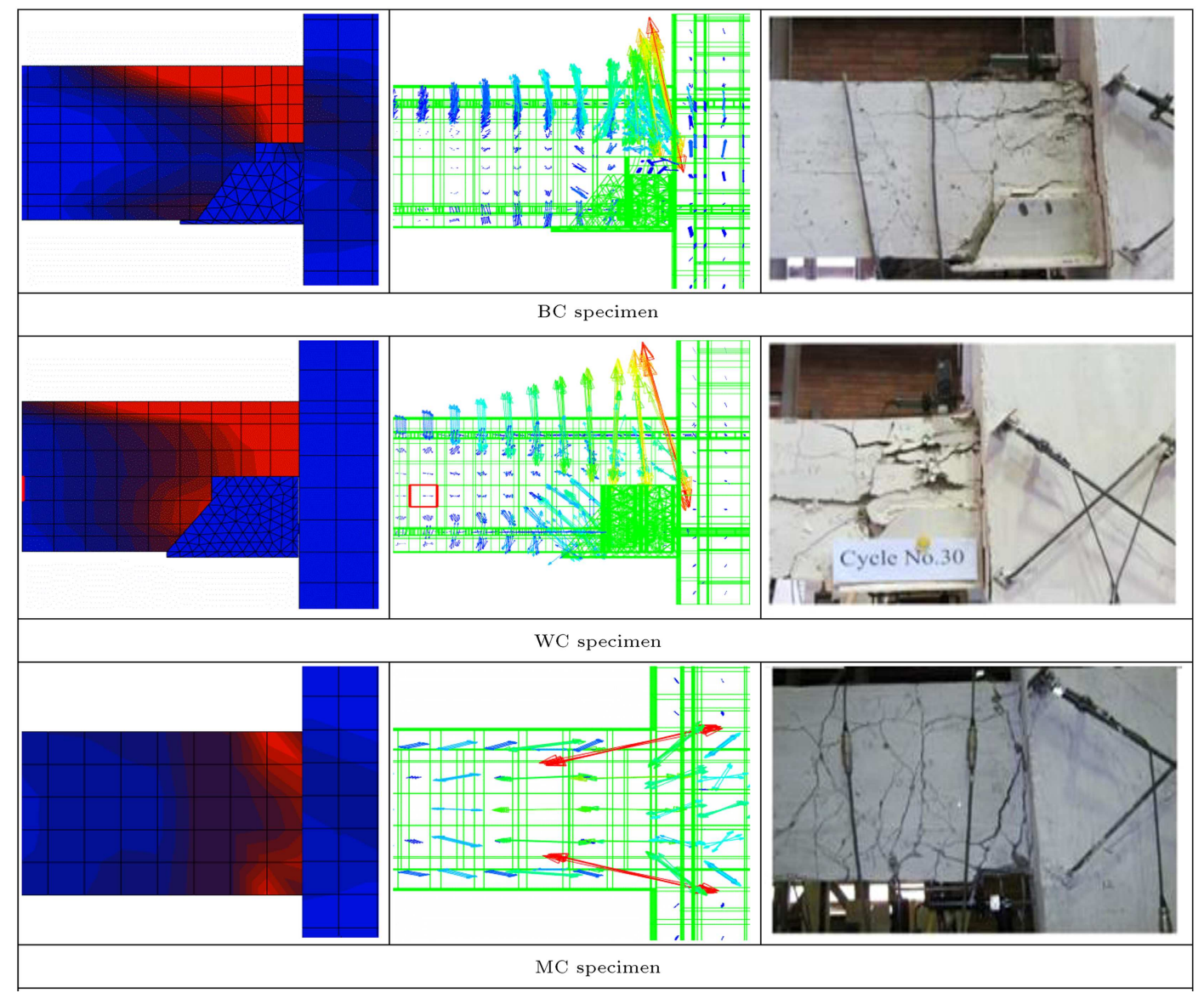

Figure 12. Comparison of crack patterns in specimens and prediction of cracks in finite-element models. 
Table 3. Mechanical characteristics of specimens.

\begin{tabular}{llcc}
\hline \multicolumn{2}{c}{ Specimen } & $\boldsymbol{\mu}$ & $\boldsymbol{\Omega}$ \\
\hline \multirow{2}{*}{ BC } & Experimental & 4.25 & 1.25 \\
& Numerical & 4.34 & 1.28 \\
& Experimental & 3.65 & 1.27 \\
WC & Numerical & 3.45 & 1.29 \\
& Experimental & 4.96 & 1.17 \\
MC & Numerical & 4.84 & 1.15 \\
\hline
\end{tabular}

depicts the crack patterns of the specimens and damage zone of finite-element models in the last step of the loading. In FE model, the direction of normal vector to the crack plane is assumed parallel to that of maximum principal plastic strain. The maximum principal plastic strain directions have been shown by red vectors. There is good agreement between fracture modes predicted by finite-element analysis and experimental observations.

\section{Conclusion}

In this research, a type of precast ductile connection was proposed and investigated through experimental and numerical studies in order to be used in momentresisting precast concrete frames. For this purpose, two specimens of the proposed connections were developed and constructed along with a monolithic specimen in full scale. Then, they were tested under reversed cyclic loading. According to the study results, the proposed connection had desirable behavior based on ACI T1.1-01. In addition, the desirable ductility factor and damage patterns of cracks showed that the proposed connection could be used in precast momentresisting concrete frames. The beam capacity factor for $\mathrm{BC}$ and $\mathrm{WC}$ specimens is somewhat bigger than that for $\mathrm{MC}$ specimen, while this is vice versa for the ductility factor of specimens. In addition, a simulation method was proposed and its accuracy was verified by experimental results. This method of study can be used for predicting the behavior of precast frames.

\section{Acknowledgements}

Financial aids of EisarGharb Company, especially the personnel of the production line during the manufacturing and production are warmly appreciated.

\section{References}

1. Kataoka, M.N., Ferreira, M.A., and El Debs A.L.H.C. "Study on the behavior of beam-column connection in precast concrete structure", Computers and Concrete., 16(1), pp. 163-178 (2015).
2. Guan, D., Guo, Z., Xiao, Q., and Zheng, Y. "Experimental study of a new beam-to-column connection for precast concrete frames under reversal cyclic loading", Advances in Structural Engineering, 19(3), pp. 529-545 (2016).

3. Choi, H.K., Choi, Y.C., and Choi, C.S. "Development and testing of precast concrete beam-to-column connections", Engineering Structures, 56, pp. 1820-1835 (2013).

4. Shariatmadar, H. and Zamani Beydokhti, E. "An investigation of seismic response of precast concrete beam to column connections: Experimental study", Asian Journal of Civil Engineering, 15(1), pp. 41-59 (2014).

5. Zoubek, B., Fahjan, Y., Fischinger, M. and Isaković, T. "Nonlinear finite element modelling of centric dowel connections in precast buildings", Computers and Concrete, 14(4), pp. 463-477 (2014).

6. Negro, P., Bournas, D.A., and Molina, F.J. "Peseudo dynamic tests on a full-scail 3-story precast concrete building global response", Engineering Structures, 57(4), pp. 594-608 (2013).

7. Bournas, D.A., Negro, P., and Molina, F.J. "Peseudo dynamic tests on a full-scail 3-story precast concrete building: Behavior of the mechanical connections and floor diaphragms", Engineering Structures, 57(4), pp. 609-627 (2013).

8. Vidjeapriya, R., Vasanthalakshmi, V., and Jaya, K.P. "Performance of exterior precast concrete beamcolumn dowelconnections under cyclic loading", International Journal of Civil Engineering, 12(1), pp. 82-95 (2014).

9. Smith, M.Z., Li, Y., and Bulleit, W.M. "A method for evaluation of longitudinal joint connections of decked precast concrete girder bridges", Structural Engineering and Mechanics, 40(3), pp. 297-313 (2011).

10. Senel, S.M. and Kayhan, A.H. "Fragility based damage assessment in existing precast industrial buildings: A case study for Turkey", Structural Engineering and Mechanics, 34(1), pp. 39-60 (2010).

11. Ertas, P., Ozden, S., and Ozturan, T. "Ductile connections in precast concrete moment resisting frames", PCI., 51(3), pp. 66-76 (2006).

12. Geraldine, S.C., William, C.S., and Nakaki, S.D., Simplified Design Procedure for Hybrid Precast Concrete Connections, National Institute of Standard and Technology (1996).

13. Han, L.H. and Li, W. "Seismic performance of CFST column to steel beam joints with RC slab: Analysis", Journal of Constructional Steel Research, 67, pp. 127139 (2011).

14. Abaqus analysis user guide "Concrete damage plasticity", Section 23.6.3 (2014).

15. Pagoulatou, M., Sheehan, T., Dai, X.H., and Lam, 
D. "Finite element analysis on the capacity of circular concrete-filled double-skin steel tubular (CFDST) stub columns", Journal of Engineering Structures, 72, pp. 102-112 (2014).

16. Murcia-Delso, J., Stavridis, A., and Shing, B. "Modeling the bond-slip behavior of confined large diameter reinforcing bars", III ECCOMAS Thematic Conference on Computational Methods in Structural Dynamics and Earthquake Engineering, Corfu, Greece (2011).

\section{Biographies}

Mojtaba Fathi was born in Kermanshah. He received his BS degree from Tehran University and his MS and $\mathrm{PhD}$ degrees from Tarbiat Modares University of Tehran in 1997 and 2004, respectively. At present, he works as an Assistant Professor at the Department of Civil Engineering in Razi University.

Mahdi Parvizi was born in Kermanshah. At the moment, he is a PhD student of Structural Civil Engineering at Razi university. He obtained his BS degree from Jondi Shapoor University of Dezfool in
2010, and his MS degree from Amir Kabir University in 2012 .

Javad Karimi obtained his BS degree in Civil Engineering from University of Tabriz in 2014; then, he received his MS degree in Structural Civil Engineering from Razi University in 2016. His thesis field concerns the modelling of precast concrete connection failure. He enjoys fluency in programming (Matlab), analysis program (Abaqus), design programs in the fields of structural design, the architecture, such as AutoCad*3d-Max*civil-3d*safe*SAP*Etabs. In addition, he is fluent in English and holds a degree in International TOEFL. He is a design engineer, supervisor, and enforcer in the Engineering Organization of Hamedan province.

Mohammad Hossein Afreidoun was born in Kermanshah. At the moment, he is a PhD student of Structural Civil Engineering at Razi University. He obtained his BS and MS degrees in Structural Civil Engineering from Islamic Azad University of Kermanshah and Razi University of Kermanshah, respectively, in 2008 and 2013. 